\title{
LA NUEVA TELEVISIÓN COMO REFUERZO DE LA NECESIDAD DE EDUCAR EN MEDIOS
}

\author{
Juan-Francisco Torregrosa Carmona: Universidad Rey Juan Carlos, Madrid \\ (España)
}

\section{Introducción: los medios de comunicación y su relación con el medio educativo}

En los momentos actuales la Educación presenta un panorama en el que se ha pasado de una cierta resistencia al cambio dentro de las aulas a contar con unos escenarios cambiantes casi sin solución de continuidad y con una nota que hace más compleja la situación: la rapidez de esos mismos cambios, lo acelerado de su desarrollo sin retorno. En la medida en que la propia escuela es una institución de marcado carácter social y como tal siempre hija de su tiempo, los procesos de enseñanza y aprendizaje han ido naturalmente evolucionando a lo largo de los días. Sin embargo, nunca antes como hoy el cambio supuso tantas realidades nuevas ni originó tanto desconcierto para tantos. En realidad para todos: profesores, alumnos, padres, instituciones... Aunque pueda resultar una alusión tópica, el destacado papel tanto de los medios de comunicación como de las tecnologías que les dan origen y soporte se halla fuera de toda duda.

Los debates más habituales en España respecto a tecnologías y medios de comunicación en la educación han girado en torno a la necesidad de contar con su presencia y su estudio dentro de los procesos formales de enseñanza. Y ello desde planteamientos tan razonables como lo\{ que ha expuesto Pérez Tornero (2000: 135): "Si la escuela tiende a ser refractaria a la incorporación de nuevas tecnologías y suele cerrarle sus puertas, éstas acaban entrando indirectamente por la ventana: quienes asisten a ella viven en un entorno cada vez más determinado por estas nuevas tecnologías". Como observa el mismo autor, no cabe tampoco pensar en la sociedad digital, con Internet a la cabeza, como un mito, aunque eso resulte lo habitual. Y conviene eludir ese riesgo porque en la actualidad las preocupaciones específicas deben ser otras. La principal dificultad no es ya, ni mucho menos, la ausencia o la escasez de dotaciones tecnológicas dentro de las aulas o incluso la resistencia a su uso, por desconocimiento o desconfianza por parte de los docentes. Antes al contrario, los aspectos que han de trabajarse más en la actualidad pasan por reforzar y valorar lo que se ha denominado como la cultura del esfuerzo. Resulta que para una mayoría de alumnos y de padres es mucho más recurrente la queja que el esfuerzo, la crítica a los demás que la autocrítica. Parece haber, en este sentido, una dejación de funciones, por así denominarlo, que contribuye a otorgar argumentos a quienes denuncian la larga crisis de la educación y el deterioro de su valoración social y, en cierta medida también, de su calidad.

No basta con echarle la culpa a la televisión, aunque sus programaciones crecientemente banales, zafias, violentas... también influyan, obviamente para mal. Hay que educar para el consumo selectivo y crítico de los medios, hay que alfabetizar a los niños en nuevas tecnologías como las que representa Internet, que

Recibido: 01/03/2005---Aceptado: 16/04/2005---Publicado: 12/11/2005 
son fuente potencial de socialización y conocimientos al tiempo que fuente igualmente potencial, y tan real a veces, de peligros y amenazas de diverso tipo. Pero que no nos pase como a aquel anciano de una reveladora viñeta de prensa de Chumy Chúmez que en su sillón delante del televisor se lamenta y exclama: "¡Es terrible. He perdido la mitad de mi vida viendo la televisión y la otra mitad criticándola!".

Lo mejor será que no tengamos posiciones apocalípticas pero que tampoco cerremos los ojos a realidades nuevas que conllevan tantas oportunidades como riesgos, tantas alegrías como decepciones, tantos usos agradecidos como fomentadores de una nueva ignorancia que elude todo lo que tenga que ver con la lecto-escritura. Hoy hay que reivindicar la lectura tradicional, el análisis y la comprensión de textos escritos, las habilidades de expresión oral, las competencias para la redacción escrita, como hace treinta, veinte y bastantes menos años se reivindicaba la presencia de las tecnologías informáticas y audiovisuales en las aulas españolas. Los medios y los lenguajes son siempre enriquecedoramente complementarios si se quiere y se sabe cómo. En este sentido, la formación del profesorado ha de ser no sólo buena en su fase inicial sino a lo largo de toda la actividad profesional.

Respecto a la necesaria presencia de las tecnologías de la información y de los medios de comunicación en la escuela, ya en los primeros años ochenta del pasado siglo veinte, la Unesco se expresaba de forma clara en el sentido de que dn lugar de condenar o aprobar el indiscutible poder de los medios de comunicación, es forzoso aceptar como un hecho establecido su considerable impacto y su propagación a través del mundo y reconocer al mismo tiempo que constituyen un elemento importante de la cultura en el mundo contemporáneo. No hay que subestimar el cometido de la comunicación y sus medios en el proceso de desarrollo, ni la función esencial de éstos en lo que atañe a favorecer la participación activa de los ciudadanos en la sociedad. Los sistemas políticos y educacionales, consideraba la institución de referencia, deben asumir las obligaciones que les incumben para promover entre los ciudadanos una comprensión crítica de los fenómenos de la comunicación. El propio organismo se refería también a los adelantos de la tecnología y la comunicación pública colectiva, unos adelantos, superados increíblemente en la actualidad, de los que los educadores responsables no hacen caso omiso, sino que, por el contrario, se esfuerzan por ayudar a sus alumnos a comprenderlos y a percibir la significación de las consecuencias que entraña especialmente su rápido crecimiento. Considerado todo ello cuando en España no había ni rastro de Internet, de la televisión a la carta, de los móviles con cámara de vídeo, etcétera.

La necesidad del análisis crítico sobre la realidad y sobre sus representaciones o construcciones mediáticas queda fuera de toda duda. Pero esa capacidad para la crítica, en el mejor y el más amplio de los sentidos, no podrá ser el fin de un proceso, sino el principio para meditar y proponer alternativas válidas en las que trabajar día a día. Hoy el problema no es ya tanto de acceso a la información como de contar con capacidad y criterios para seleccionar, para descubrir las fuentes, evaluar la credibilidad de sus mensajes y ser capaz de elaborar contenidos propios 
de calidad y de conocer no sólo los productos mediáticos sino también, aspecto fundamental, los procesos característicos de la comunicación pública colectiva.

La Educación para la Comunicación ha sido reivindicada por expertos internacionales y españoles desde hace decenios, como ámbito conectado con los temas transversales del currículum, lo que justifica su inserción dentro del sistema educativo, al implicar todo un conjunto de actitudes, procedimientos y contenidos tan significativos como aquellos a los que remite tal concepto de transversalidad en la enseñanza obligatoria (la educación para la paz, para la salud, educación en la igualdad de género, educación vial, etcétera). Por tanto, lo que se defiende es la contribución al enriquecimiento de la realidad diaria del aula, a la educación en sí, que es tanto presencial como mediática, es decir, proviene también de los medios, cuya dimensión educadora, o sus efectos des-educadores, si se prefiere, no cabe obviar. $\mathrm{Y}$ ha de atenderse en particular a la televisión y a Internet por su alta penetración en los hogares, su difusión, su mayor impacto y la mayor complejidad de lo que aparentan su funcionamiento y sus contenidos, en ambos casos, para el espectador, en especial para el de menor edad o en mayor riesgo potencial.

Los profesores deben realizar un ejercicio de revisión de sus propias actuaciones, pero es tan relevante como eso que las instituciones y los partidos políticos que las sustentan sean capaces de ponerse de acuerdo en un tema tan sensible como el de la educación, en el que un país se juega prácticamente todo. Ya decía Jovellanos que, siendo muchas las fuentes de la prosperidad social, todas tienen un mismo origen, y ese origen no es otro que la educación. En ámbitos básicos como la educación, todas las fuerzas políticas deberían ser capaces de lograr acuerdos o pactos de Estado dignos de tal nombre. De manera que el marco legislativo, sea, por ejemplo, mucho más estable de lo que lo viene siendo en nuestro país respecto a la educación obligatoria. Se trata de lo más sensible de una sociedad: sus niños y sus jóvenes. Digámoslo una vez más: no hay aprendizaje sin esfuerzo, no hay aprendizaje sin motivación, no hay garantías sin suficiente inversión pública, sin suficiente esfuerzo de los profesores, de los padres, de la sociedad toda...

Pasemos de los diagnósticos y los deseos a los hechos y los avances. Seamos capaces de aprovechar una verdad irrefutable constatada por un fotógrafo contemporáneo como el brasileño Sebastião Salgado tras visitar y retratar los países más pobres y desheredados del mundo: "donde hay escuela, hay esperanza".

Existe hoy, en definitiva, una ineludible responsabilidad social que debe llevar a todos los agentes a acompañar a la educación en su viaje continuo desde el inmovilismo y una cierta resistencia al cambio hasta la necesidad de transitar por caminos que le deparan cambios drásticos, bastante rápidos y con toda seguridad sin posibilidad de volver sobre sus pasos. Pero deberá ser un acompañamiento en modo alguno pasivo, sino participante, desde la consciencia ilusionada de saber lo que una sociedad se juega.

\section{Las nuevas expresiones televisivas como refuerzo de la necesidad de educar en comunicación}

\subsection{Cómo es la"televisión de hoy}


La televisión en España se halla dominada hoy por la extensión de lo que se denominó la "cultura mosaico" (Moles). En esa línea, la fragmentación del mensaje delevisivo, su falta de estructura, su superposición no se produce únicamente en las fases de elaboración y transmisión sino también desde la óptica del receptor dada su forma y ritmo de consumo (el zapping, por ejemplo), y los propios espacios. Todo está hoy mucho más fragmentado. En muchos tratamientos se intenta eludir la fugacidad de las noticias y profundizar pero en realidad cada vez los mensajes son már cortos en espacio y tiempo para adaptarse tanto a un canal que así lo exige como a un receptor habituado, educado así. Nos encontramos ante unas relativamente nuevas expresiones mediáticas compuestas por mil estímulos pero caracterizadas por lo efímero y lo fragmentario en la exposición y en el consumo. Los contenidos de todo tipo a los que sirve como plataforma Internet son una muestra más de ello. Incluso en las noticias de mayor entidad o alcance, se evidencia que la fragmentación afecta tanto a la emisión como a la recepción del mensaje, debido a los nuevos tratamientos informativos y documentales. Cebrián (2004: 61) destaca cómo la programación televisiva "parte de una planificación, distribución y ordenación de contenidos. Los canales generalistas seleccionan, distribuyen y ordenan los contenidos conforme a los comportamientos sociológicos de las audiencias, no según la vinculación de unos con otros. No hay sistematización, sino heterogeneidad y combinaciones no coherentes. La coherencia está marcada por la estructura interna y por los horarios, por el potencial de audiencia presente ante el televisor".

Junto con la fragmentación, el avance del espectáculo. Dos notas prácticamente indisociables en las actuales fórmulas narrativas presentes en la televisión. El ingrediente espectacular de los contenidos televisivos ha sido abordado, dentro de las teorías del espectáculo, por autores precursores como Guy Debord, Jean Baudrillard o Furio Colombo.

Un tema crucial ante el que nos sitúa la imagen en general y la televisual en particular, dado su alcance y su influencia, es el que implica un concepto clave para las Ciencias de la Comunicación: la representación. Y consiguientemente el de la construcción social, especialmente del ámbito mediático, de la realidad. Estos aspectos han sido abordados en ocasiones recurriendo a referencias filosóficas básicas como las del Mito de la Caverna de Platón. Los esclavos de la caverna toman por realidad lo que son sólo sombras. Y sin embargo, la imagen de la realidad no es la realidad. Hay que acudir a lo que en principio es tautología para descubrir que muchísimos receptores no tienen ninguna conciencia de lo evidente del aserto. Es más: estarían dispuestos a sostener lo contrario o a actuar, en su caso, sin someter la apariencia al raciocinio. En el mundo de la imagen, sobre todo en el de la imagen en movimiento, pero también el caso de las fotografías y otros medios de expresión icónica, entran en directa colación los binomios razón/emoción, idea/sentimiento, argumento/pasión, y un largo etcétera. Por eso es tan grande su influencia y por eso se hace necesaria una alfabetización mediática o multimedia de carácter global.

La distinción que se hace entre representación y realidad, entre una imagen y su referente, entre significante y significado, es fundamental en la enseñanza de los 
medios. Para los autores de referencia, el primer principio de la educación audiovisual es que los medios son sistemas simbólicos, o de signos, que necesitan ser leídos activamente y que no reflejan sin más la realidad externa. Antes al contrario, los medios actúan como agentes activos de los procesos de construcción o representación de la realidad, en lugar de limitarse simplemente a transmitirla o reflejarla de un modo aséptico y neutral. Geneviève Jacquinot (1996) ofrece una consideración de utilidad: que el pensamiento visual existe, como escribió Rudolf Arnheim, uno de los primeros en defenderlo con argumentos convincentes según los cuales las operaciones cognitivas designadas con la palabra "pensamiento" lejos de ser el patrimonio de procesos mentales que intervienen en un nivel que se encuentra por encima y más allá de la percepción, constituyen los ingredientes fundamentales de la percepción misma. La autora se refiere a aquellas operaciones que consisten en explorar activamente, seleccionar, aprehender lo esencial, simplificar, abstraer, analizar y sintetizar, completar, comparar, y resolver dificultades, así como también combinar, clasificar y ubicar en un contexto. En este sentido, es preciso reivindicar el "paradigma de la representación" como la mejor forma de diagnosticar la situación actual, mediante el trabajo analítico oportuno, tanto desde el ámbito profesional como desde los espacios propios de la labor epistemológica dentro de diversos campos, entre ellos las Ciencias de la Comunicación.

Resulta imprescindible abordar la interpretación de los contenidos audiovisuales y redoblar los esfuerzos por efectuar una lectura crítica de la información icónica y sonora de los medios, sin olvidar ninguna de las dimensiones implicadas: carga simbólica, trasfondo ideológico, aspectos estéticos, el propio proceso de producción informativa, coyuntura en la que se realiza la presentación, la dotación de sentido por parte del receptor dadas las condiciones y situaciones creadas a partir de los fragmentarios, efímeros y espectaculares relatos televisivos habituales, entre otros aspectos. Como destaca la doctrina, los documentos audiovisuales son comunicación mediada. No se puede decir que sean ventanas abiertas al mundo o espejos de la sociedad. Ferrés (1999) explica que la conocida expresión sobre la televisión como ventana, exponente de la idea mítica sobre la objetividad de los medios, se debe a la obra publicada por Hutchinson: Aquí está la televisión: su ventana al mundo (1946). Aunque imitan la realidad, esas representaciones televisivas o mediáticas en general, por definición, no son "reales". Gran parte de su éxito reside precisamente en su aparente naturalidad. Y esa nueva forma recreación tecnológica de la realidad puede y debe en muchos casos llevarnos a cuestionar la cultura audiovisual y a enseñar a pensar precisamente en la propia realidad frente a la información mediada.

En el caso concreto del medio televisivo, éste ofrece hoy un discurso en el que se ha exacerbado otra característica inherente al medio, en lógica sintonía con las ya anotadas de espectáculo y fragmentación: lo efímero de sus contenidos. El problema surge sobremanera respecto al ámbito informativo, respecto a la vertiente periodística. Muchos autores, como Kapuscinski, han alertado sobre los riesgos de no realizar prácticamente ningún seguimiento a los grandes hechos informativos, más allá de la duración de la polémica del momento. Las nuevas expresiones de la televisión son el máximo exponente de esa realidad, a parte de la dinámica que demuestra claramente, como el mismo autor polaco destacó, que lo que interesa a los medios de comunicación ya no es reproducir la realidad sino ganar a la 
competencia, por encima de cualquier otra cosa. De ahí que se aumenten los límites de lo que antes se consideraba tolerable respecto a la exhibición más impúdica de todo tipo de hechos pertenecientes a la intimidad, por ejemplo. $O$ del tratamiento informativo de la muerte y del dolor ajeno. O de ahí que interese tanto a la industria televisiva indagar en la realidad identitaria, aparente o real, que más pueda atraer a la audiencia hacia unos personajes hechos a la medida de las necesidades del medio. Unos personajes cuya aceptación o rechazo personal poco importa, siempre y cuando no dejen indiferentes a los espectadores y consigan lograr su atención. A la sobreabundancia de producción informativa y también su nueva forma de consumo fragmentario, descontextualizado muchas veces, muy limitado desde el punto de vista espacio-temporal e incluso de su documentalidad, le acompaña la hibridación entre contenidos informativo-periodísticos y publicitario-propagandísticos. El modelo mediático vigente pasa también por un tratamiento de la actualidad en el que los secretos o supuestos secretos, tan relacionados con la memoria y con la identidad, juegan un papel central. Así, es cada vez más frecuente acudir a hemerotecas y archivos para rescatar viejas noticias o reportajes, episodios controvertidos o escabrosos para los programas de la prensa rosa televisiva en los que se hacen eco de temas cuya memoria se refresca con pretensiones de polemizar. A esos sucesos y protagonistas del pasado se les presenta una relación con el presente que generalmente es artificial: construida por la propia televisión. Se trata de toda una industria mediática de la nostalgia.

\subsection{Cómo educar hoy en medios}

La influencia de la educación para los medios ha crecido en los últimos años, sobre todo en países de América Latina, pero también en muchos otros, entre ellos España. En todos estos lugares, y en otros, se han logrado avances, más o menos o considerables, en el sentido de introducir en el currículum escolar el estudio, el uso como recursos educativos, la creación y el análisis en torno a los diversos medios de comunicación, como la prensa escrita y los audiovisuales, en particular la televisión, dada su influencia y su penetración en prácticamente todos los hogares. En los que, como señalan algunos autores, en una acertada imagen metafórica, el televisor (los diversos televisores, hasta tres y cuatro en muchas casas) ocupa hogaño el lugar que antaño tuvo el fuego primigenio y aglutinador.

La educación para los medios hace hincapié en la necesidad de propiciar en niños y jóvenes una lectura y una recepción crítica de los mensajes provunientes de los distintos medios; todo ello, ynsistimos, mediante la reflexión y el análisis. Un aspecto determinante es que los alumnos aprendan los lenguajes para que ellos mismos puedan expresarse y realizar sus propios contenidos audiovisuales o literarios, fomentando con ello su creatividad y su capacidad para ofrecer alternativas estévicas o ideológicas en sentido amplio (propuestas sobre valoración del entorno y sus circunstancias, refuerzo de determinados valores sociales, etcétera), desde una concepción constructivista en la que el alumno es protagonista de su propio proceso de aprendizaje, descubrimiento y experimentación.

Desde hace más de tres decenios, con el término edu-comunicación o Educación para los Medios se hace referencia a todas la formas de estudiar, aprender y enseñar, a todos los niveles, y en toda circunstancia, la historia, la creación, la 
utilización y la evaluación de los medios de comunicación como artes prácticas y técnicas, así como el lugar que ocupan los medios de comunicación en la sociedad, su repercusión social, las consecuencias de la comunicación mediatizada, la participación, la modificación que producen en los modos de percepción y el papel del trabajo creador y el acceso a los medios de comunicación. Ya en los inicios, se entendía que los sistemas políticos y educacionales deben asumir las obligaciones que les incumben para promover entre los ciudadanos una comprensión crítica de los fenómenos de la comunicación. Algunas líneas de actuación podrían, según la Unesco, anteriormente citada, hacer más eficaz la educación: 1. Organizar y apoyar programas integrados de educación relativa a los medios de comunicación desde el nivel preescolar hasta el universitario y la educación de adultos, con vistas a desarrollar los conocimientos, técnicas y actitudes que permitan favorecer la creación de una conciencia crítica y, por consiguiente, de una mayor competencia entre los usuarios de los medios de comunicación electrónicos e impresos. 2. Desarrollar cursos de formación para los educadores y diferentes tipos de animadores y mediadores encaminados tanto a mejorar su conocimiento y comprensión de los medios de comunicación como a familiarizarlos con métodos de enseñanza apropiados que tengan en cuenta el conocimiento de los medios de comunicación a menudo considerable, pero aún fragmentario, que posee ya la mayoría de los estudiantes. 3. Estimular las actividades de investigación y desarrollo concernientes a la educación sobre los medios desde una perspectiva multidisciplinar.

En el ámbito de los expertos, Masterman (1993) aboga por una enorme ampliación de la conciencia crítica y el desarrollo coherente de programas educativos que fomenten la autonomía. Los acontecimientos, pasados o presentes, avalan la teoría de este autor que considera a los medios de comunicación como auténticas empresas de concienciación. En el caso del trabajo teórico-práctico con el medio televisivo en la enseñanza hay que ser conscientes de algo definitivo, en lo que coincide la mayor parte de la doctrina más autorizada: “¿Cómo no hacer entrar la televisión en la escuela, si ya está dentro, quiérase o no, por la influencia que ejerce sobre los saberes, las actitudes y los comportamientos de los alumnos? La televisión siempre es educativa, aunque lo sea de una manera que escape a la pedagogía" (Jacquinot, 1996: 10). Una vez constatado que el medio por excelencia es, como el resto de soportes, siempre educativo, a la escuela corresponderá enseñar a sus miembros a ver la televisión, a leer todos los medios en el aula. Es la idea que ha animado las investigaciones de autores como Aguaded (2000) o García Matilla (2003), quienes junto a otros expertos y a multitud de maestros y profesores llevan también años abogando en España por adquirir una "competencia televisiva" desde la escuela y por vincular provechosamente ambas realidades: televisión y educación. Hoy es necesario seguir en ello. Como escribe Joan Ferrés (1999: 102) en una frase bien ilustrativa, "una escuela que no enseña a ver la televisión es una escuela que no educa".

\section{A modo de conclusión}

Las nuevas expresiones televisivas suponen una muestra evidente de la necesidad de redoblar y actualizar los esfuerzos en materia de edu-comunicación dentro de los procesos formales de enseñanza y aprendizaje. Respecto a las características del 
modelo televisivo imperante, debe tenerse en cuenta que ni los discursos ni las prácticas productivas o rutinas profesionales nunca son completamente autónomos.

Siguiendo el hilo de esa lógica argumental, lo peor no es la existencia, incluso legítima a priori, de un tratamiento espectacular o frívolo para los géneros y los programas televisivos propios de la industria del entretenimiento, sino que, con frecuencia, ese modo de hacer acaba influyendo cuando no atravesando directamente los relatos informativos de temas "serios", por así decirlo, en los que una sociedad democrática, dominada por la omnipresencia de medios y tecnologías, se juega mucho. Dadas, de nuevo, las notas actuales del discurso televisivo, e indagando en algunos de los motivos que lo han originado tal cual aparece hoy, se podría realizar un cierto ejercicio de prospectiva para intentar apuntar si se confirmarán las tendencias en marcha. $Y$ parece probable que así sea. Con un mercado de audiencias cada vez más reñido, parece lógico pensar que hay suficiente base para creer que la lucha por las miradas del espectador siga sacrificando la calidad general de los contenidos.

Una constatación como la de la repetición de contenidos y fórmulas programáticas, la mayoría de ellas importadas desde la industria televisiva internacional, en particular la norteamericana, seguirá siendo habitual. Aunque muchas veces es inconfundible el sesgo o la adaptación autóctona que hace la televisión en España respecto a su programación, el éxito viene generalmente dado por la importación de formatos.

En definitiva, todas estas características que presentan las nuevas expresiones y programaciones televisivas constituyen hoy un poderoso motivo más para proseguir la labor siempre inacabada y siempre necesaria de la educación en medios.

\section{Referencias}

AGUADED, J. I. (2000). Convivir con la televisión. Barcelona, Paidós.

CEBRIÁN HERREROS, M. (2004): Modelos de televisión: generalista, temática y convergente con Internet. Barcelona, Paidós Papeles de Comunicación.

FERRÉS I PRATS, J. (1999): Televisión y mducación. Barcelona, Paidós.

GARCÍA MATILLA, A. (2003). Una televisión para la educación. La utopía posible. Barcelona, Gedisa.

JACQUINOT, G. (1996): La escuela frente a las pantallas. Buenos Aires, Aique.

MASTERMAN, L> (1993): La enseñanza de los medios de comunicación. Madrid, De la Torre.

PÉREZ TORNERO, J. M. (comp). (2000). Comunicación y Educación en la Sociedad de la Información, Barcelona, Paidós. 